\title{
Support for major hypotheses in invasion biology is uneven and declining
}

\author{
Jonathan M. Jeschke ${ }^{1,2,3}$, Lorena Gómez Aparicio4, Sylvia Haider', Tina Heger ${ }^{1,5}$, \\ Christopher J. Lortie 6 , Petr Pyšek ${ }^{7,8}$, David L. Strayer ${ }^{2}$
}

I Technische Universität München, Department of Ecology and Ecosystem Management, Restoration Ecology, DE-85350 Freising-Weihenstephan, Germany 2 Cary Institute of Ecosystem Studies, Box AB, Millbrook, NY 12545, USA 3 Ludwig-Maximilians-University Munich, Department of Biology II, Ecology, Grosshaderner Str. 2, DE-82152 Planegg-Martinsried, Germany 4 Instituto de Recursos Naturales y Agrobiología de Sevilla (IRNAS), CSIC, Box 1052, Sevilla ES-41080, Spain 5 University of California, Department of Plant Sciences, One Shields Ave., Davis, CA 95616, USA 6 York University, Department of Biology, Toronto, ON M3J 1P3, Canada 7 Institute of Botany, Academy of Sciences of the Czech Republic, CZ-252 43 Prühonice, Czech Republic 8 Charles University in Prague, Faculty of Science, Department of Ecology, Viničná 7, CZ-128 44 Prague 2, Czech Republic

Corresponding author: Jonathan M. Jeschke (jonathan.jeschke@gmx.net)

Academic editor: Brad Murray | Received 29 May 2012 | Accepted 9 August 2012 | Published 22 August 2012

Citation: Jeschke JM, Gómez Aparicio L, Haider S, Heger T, Lortie CJ, Pyšek P, Strayer DL (2012) Support for major hypotheses in invasion biology is uneven and declining. NeoBiota 14: 1-20. doi: 10.3897/neobiota.14.3435

\begin{abstract}
Several major hypotheses have been proposed to explain and predict biological invasions, but the general applicability of these hypotheses is largely unknown, as most of them have not been evaluated using a standard approach across taxonomic groups and habitats. We offer such an evaluation for six selected leading hypotheses. Our global literature review reveals that those hypotheses that consider interactions of exotic invaders with their new environment (invasional meltdown, novel weapons, enemy release) are better supported by empirical evidence than other hypotheses (biotic resistance, island susceptibility, tens rule). We also show that empirical support for the six hypotheses has declined over time, and that support differs among taxonomic groups and habitats. Our results have implications for basic and applied research, policy making, and invasive species management, as their effectiveness depends on sound hypotheses.
\end{abstract}

\section{Keywords}

Biological invasions, biotic resistance hypothesis, decline effect, enemy release hypothesis, invasional meltdown hypothesis, island susceptibility hypothesis, novel weapons hypothesis, tens rule

Copyright Jonathan M. Jeschke et al. This is an open access article distributed under the terms of the Creative Commons Attribution License 3.0 (CC-BY), which permits unrestricted use, distribution, and reproduction in any medium, provided the original author and source are credited. 


\section{Introduction}

Invasion biologists... need to take a good hard look at the fundamental tenets of the discipline and ensure that our understanding is built on hard evidence rather than assumptions, or on theories that have equivocal empirical support.

Moles et al. 2012

Invasive species are those that have been introduced to regions beyond their native range, established in the wild, and spread substantially from their point of introduction (Lockwood et al. 2007; Blackburn et al. 2009; Hulme et al. 2009). They can threaten global biodiversity, introduce diseases, cause other ecological problems, or incur economic costs (Pimentel et al. 2005; Kettunen et al. 2009; Pyšek and Richardson 2010). Studying biological invasions promises to both help mitigate impacts by invaders and better understand basic principles of ecology and evolution (Sax et al. 2007). Although research on biological invasions has a long tradition, publications on this topic have been numerous only since the 1990s (Darwin 1859; Elton 1958; Cadotte 2006; Davis 2006; Richardson and Pyšek 2008). From this perspective, invasion biology is still a young discipline (Pyšek and Hulme 2009). Its major hypotheses are logical and appealing, but the extent of empirical evidence supporting them is largely unknown (Moles et al. 2012). Some overviews of the level of support for individual hypotheses exist (e.g. Jeschke and Strayer 2005; Liu and Stiling 2006; Levine et al. 2004; Moles et al. 2012), but to our knowledge, no comparative evaluation of multiple major hypotheses across the entire range of taxonomic groups of invading species and invaded habitats is currently available. Such an evaluation is a critical step for any discipline, as it identifies research gaps, discriminates hypotheses with substantial support from those lacking it, and defines future priorities.

In this article, we evaluate six major hypotheses in invasion biology. Our evaluation is based on a standardized literature analysis across animals and plants in terrestrial and aquatic habitats. The six focal hypotheses represent a broad cross-section of the field and capture a variety of mechanisms thought to play a role in biological invasions (cf. Jeschke et al. 2012):

1) Biotic resistance hypothesis: ecosystems with high biodiversity are more resistant against invaders than ecosystems with low biodiversity (Elton 1958; Levine and D’Antonio 1999; Lonsdale 1999; Mack et al. 2000; Maron and Vilà 2001; Shea and Chesson 2002; Levine et al. 2004; Fridley et al. 2007; Jeschke and Genovesi 2011). This formulation of the biotic resistance hypothesis is also known as diversity-invasibility hypothesis. It is important not only for invasion biology but also for the question of whether diversity affects ecosystem stability (Ives and Carpenter 2007).

2) Island susceptibility hypothesis: invasive species are more likely to become established and have major ecological impacts on islands than on continents (Elton 1958; Simberloff 1995; Shea and Chesson 2002; Jeschke 2008). This hypothesis is related to 
the biotic resistance hypothesis, as continents typically have higher biodiversity than islands, mainly due to geographic and thus evolutionary isolation.

3) Invasional meltdown hypothesis: the presence of invasive species in an ecosystem facilitates invasion by additional species, increasing their likelihood of survival or ecological impact (Simberloff and Von Holle 1999).

4) Novel weapons hypothesis: in the exotic habitat, invasive species can have a competitive advantage against native species because they possess a novel weapon, i.e. a trait that is new to the resident community of native species and therefore affects them negatively (Callaway and Aschehoug 2000; Callaway and Ridenour 2004). Prime examples of novel weapons are plant biochemicals with allelopathic effects, but traits of other organisms can be considered as novel weapons as well, e.g. toxic substances produced by invasive cane toads (Bufo marinus).

5) Enemy release hypothesis: the absence of enemies in the exotic range is a cause of invasion success (Maron and Vilà 2001; Keane and Crawley 2002; Mitchell and Power 2003; Torchin et al. 2003; Colautti et al. 2004; Liu and Stiling 2006; Blumenthal et al. 2009).

6) Tens rule: approximately $10 \%$ of species successfully take consecutive steps of the invasion process: about $10 \%$ of species transported beyond their native range will be released or escape in the wild (they are called introduced species or casuals); about $10 \%$ of these introduced species will be able to establish themselves in the wild; and about $10 \%$ of species established will become invasive/pest species (Williamson and Brown 1986; Williamson 1996; Jeschke and Strayer 2005; Jeschke 2008).

There are other major hypotheses in invasion biology, but these six represent a broad cross-section of the discipline (Shea and Chesson 2002; Hierro et al. 2005; Dietz and Edwards 2006; Richardson and Pyšek 2006; Lockwood et al. 2007; Pyšek et al. 2008; Blackburn et al. 2009; Catford et al. 2009; Atwood and Meyerson 2011; Moles et al. 2012). Two of the hypotheses focus on ecosystems into which invaders were introduced (biotic resistance and island susceptibility), one focuses on the invaders themselves (tens rule), and the remaining three focus on invader-ecosystem interactions (invasional meltdown, novel weapons, enemy release).

\section{Methods}

Using the Web of Science, we systematically searched the literature for empirical studies across taxonomic groups and habitats that tested each of the six hypotheses. Our search terms consisted of: (1) a specific search term for each hypothesis, and (2) a general search term to restrict results to studies on non-native species. The following 
general search term was applied for all hypotheses: (alien OR exotic OR introduced OR invasive OR naturali?ed OR nonindigenous OR non-native). The exact full search terms for the hypotheses are given in Table 1. Literature searches were carried out between February and May 2010 (see Table 1) and returned more than 3500 articles. We screened the titles and abstracts of these articles to identify potentially relevant articles for our study. We then consulted the full texts of these articles and checked references cited therein to find further relevant articles that were not returned by the Web of Science search. All relevant empirical studies that we found with our systematic search were included in the analysis. Theoretical studies, reviews, and meta-analyses were not included. We did include studies cited in reviews and meta-analyses, however. Some articles are included more than once in our analysis, as they have tested several hypotheses or sub-hypotheses (see the hierarchy-of-hypotheses approach below). Our analysis is restricted to publications in scientific journals. We excluded book chapters because they are not currently included in the Web of Science. Book chapters are also not as easily accessible as journal papers. In total, we identified 371 empirical tests of the focal hypotheses.

\section{The hierarchy-of-hypotheses $(\mathrm{HoH})$ approach}

We used a novel approach to analyze these 371 empirical tests. This approach, which we call hierarchy-of-hypotheses $(\mathrm{HoH})$ approach, captures the complexity of major hypotheses by hierarchically structuring them into smaller sub-hypotheses. We developed this approach for invasion biology, but it can be easily applied to other disciplines

Table I. Search terms for hypotheses.

\begin{tabular}{l|l|c}
\hline Hypothesis & Search term & Date of search \\
\hline $\begin{array}{l}\text { Biotic } \\
\text { resistance, island } \\
\text { susceptibility }\end{array}$ & $\begin{array}{l}\text { (biotic resistance OR resistance hypothesis } \\
\text { OR diversity-invasibility hypothesis OR island } \\
\text { susceptibility) AND general search term }\end{array}$ & 19 Feb 2010 \\
\hline $\begin{array}{l}\text { Invasional } \\
\text { meltdown }\end{array}$ & meltdown AND general search term & 18 Mar 2010 \\
\hline Novel weapons & $\begin{array}{l}\text { ("novel weapon*" OR “allelopathic advantage } \\
\text { against resident species" OR AARS) OR } \\
(\text { (weapon* OR allelopath*) AND general search } \\
\text { term) }\end{array}$ & 26 May 2010 \\
\hline Enemy release & enemy release AND general search term & 17 Feb 2010 \\
\hline Tens rule & $\begin{array}{l}\text { (tens rule OR establishment success) AND } \\
\text { general search term }\end{array}$ & 19 Feb 2010 \\
\hline
\end{tabular}

\footnotetext{
† The search for these related hypotheses was combined.

¥ The general search term was: (alien OR exotic OR introduced OR invasive OR naturali?ed OR nonindigenous OR non-native).
} 
as well. Researchers empirically testing a major hypothesis do not usually test it in all of its complexity. Most major hypotheses are not even empirically testable as such, as they are too broad and unspecific. As a result, researchers typically test a certain sub-hypothesis of the major hypothesis, although they are rarely explicit about this restriction. The $\mathrm{HoH}$ approach reflects this observation by formulating hypotheses in a way that makes them better testable (see the formulations of our six focal hypotheses), and by further dividing them into testable sub-hypotheses, as far as necessary. For example, the formulation "ecosystems with a high biodiversity are more resistant against invaders than ecosystems with a low biodiversity" which we used for the biotic resistance hypothesis is only one of the possible versions of this hypothesis. It can be further divided into sub-hypotheses, especially because biodiversity and resistance can be defined and measured in different ways. For example, a sub-hypothesis of the biotic resistance hypothesis is that native species richness (a measure of native biodiversity) is negatively correlated with establishment success of introduced species, defined as the fraction of introduced species that become established (an inverse measure of resistance). Further sub-hypotheses are formulated accordingly and included in the hierarchy of hypotheses (Fig. 1).

The $\mathrm{HoH}$ approach ensures application of the same yardstick to all empirical studies that are being evaluated. As different versions of a given hypothesis exist, it sometimes happens that two authors with similar empirical results come to opposite conclusions: the first author applies version $a$ of a given hypothesis and finds that the

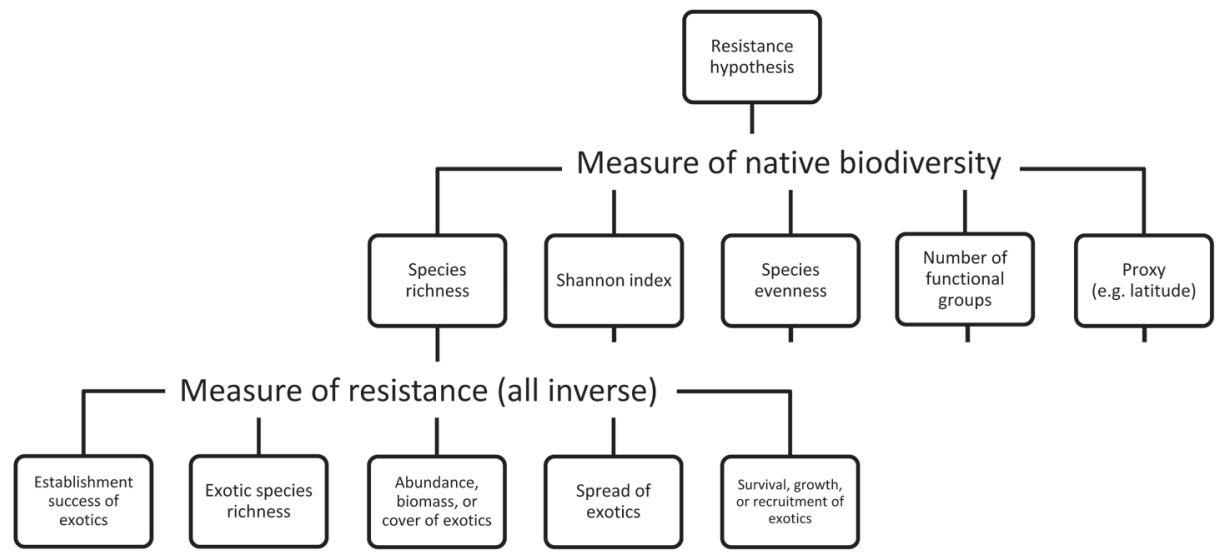

Figure I. Example of a hierarchy of hypotheses. The biotic resistance hypothesis (as defined in the main body text) can be divided into sub-hypotheses according to the different measures (and thus definitions) of native biodiversity and resistance against invaders. Note that all measures of resistance typically applied are inverse measurements: the quantity measured reflects the susceptibility of ecosystems against invaders, so its inverse reflects resistance against invaders. Each of the five sub-hypotheses corresponding to different measures of biodiversity branch into five sub-sub-hypotheses corresponding to different measures of resistance against invaders. For illustrative purposes, the second branching is only shown for one subhypothesis (species richness as a measure of biodiversity). 
data are in line with this version, whereas the second author applies version $b$ of the hypothesis and finds the data are not in line with this version. Such discrepancies lead to a bias if all studies' conclusions are simply adopted, as is typically done in ordinary vote counting. The $\mathrm{HoH}$ approach solves this problem by comparing each study's results to standard criteria.

Similarly, the $\mathrm{HoH}$ approach ensures that only studies are included that test the major hypothesis as formulated and represented in the $\mathrm{HoH}$. For example, the biotic resistance hypothesis is sometimes formulated in a broader way than we did here, by also considering effects of disturbance on resistance against invaders (e.g. Mack et al. 2000; Jeschke and Genovesi 2011; and references therein). We did not include studies investigating such effects, even though many of these studies include the term "resistance hypothesis" in their title or abstract. We do not claim that the formulation of the resistance hypothesis proposed here is the correct one. We do not even think there is a single correct formulation of a given hypothesis. It is, however, important to clearly state the hypothesis one is addressing, and the $\mathrm{HoH}$ approach helps doing that.

The $\mathrm{HoH}$ approach can be combined with fully quantitative analyses, e.g. metaanalyses based on effect sizes (Arnqvist and Wooster 1995; Gurevitch and Hedges 2001). Effect sizes can be extracted from published empirical tests of individual subhypotheses and be combined to evaluate support for a given major hypothesis. However, when comparatively evaluating multiple major hypotheses, one is often confronted with very heterogeneous data that can sometimes not all be reduced to a single effectsize metric, such as $d$ (Gurevitch and Hedges 2001) or a correlation coefficient. A comparative evaluation would only be meaningful if a single effect-size metric can be used for all hypotheses. This was not the case for our hypotheses, hence we applied a semi-quantitative analysis, counting the number of studies that either support, question/oppose, or are undecided/inconclusive about each sub-hypothesis.

Let us look at an example to illustrate how studies were classified as supporting, questioning, or being undecided. For the sub-hypothesis of the biotic resistance hypothesis that is depicted in the lower left of Fig. 1, a study showing a significant (or otherwise statistically supported, e.g. by means of information-theoretic or Bayesian approaches) negative relationship between establishment success of exotics and native species richness would support this sub-hypothesis; a study showing a positive relationship or not detecting any relationship (with sufficient sample size to detect one) between establishment success of exotics and native species richness would question the sub-hypothesis; and a study showing inconsistent relationships, e.g. for different experimental setups, would be undecided about this sub-hypothesis. A study showing a relatively clear negative relationship, but without statistical support (e.g. due to low sample size), would also be classified as undecided; however, such studies are rare. For each study that we analyzed, we noted whether its conclusion regarding a given sub-hypothesis is based on statistical analysis that went beyond simple descriptive statistics such as means, medians, or standard errors. Typical examples of such statistical analysis are null-hypothesis significance testing or information-theoretic or Bayesian approaches. Taking aside empirical tests of the 
tens rule, the conclusions of 293 out of 297 tests $(98.7 \%)$ were based on statistical analysis defined in this way.

For the tens rule, the situation was a bit different, as many authors did not statistically compare their observed transition probability to those predicted by the tens rule. It is not commonly agreed upon if the data should be used to calculate a confidence interval for the transition probability and then see if it overlaps with the $10 \%$ value predicted by the tens rule, or if alternatively the observed transition probability should be compared to the 5-20\% range suggested by Williamson (1996). These approaches are similar (as the 5-20\% range was derived by considering confidence intervals and other aspects), but they are not the same. We followed Williamson's suggestion; hence, if a study reported a transition probability between 5 and $20 \%$, we classified it as supporting the rule; if the transition probability was $<5 \%$ or between 20.01 and $25 \%$, we classified the study as undecided; and if the transition probability was $>25 \%$, we classified the study as questioning the tens rule.

In following the $\mathrm{HoH}$ approach, we subdivided the different hypotheses and sub-hypotheses as far as necessary, i.e. hypotheses and sub-hypotheses that were tested only by a few studies were not further divided (Table 2). In principle, our approach allows evaluation of empirical support for each sub-hypothesis. Such a detailed analysis of each sub-hypothesis is beyond the scope of this article, however, where we want to focus on overall support for the six major hypotheses. We thus summed up figures of empirical support for each sub-hypothesis to give total numbers for each major hypothesis. We then contrasted the hypotheses to assess whether they were empirically supported in general, whether differences in support exist among taxonomic groups (plants, invertebrates, vertebrates) or habitats (terrestrial, freshwater, marine), and whether published tests are lacking for specific taxonomic groups or habitats.

Table 2. All hypotheses and sub-hypotheses evaluated in this study.

\begin{tabular}{|c|c|}
\hline Hypothesis no. & Description $^{\dagger}$ \\
\hline 1 & Biotic resistance hypothesis $(n=129)$ \\
\hline 1.1 & $\begin{array}{l}\text { Sub-hypothesis with species richness as measure of native } \\
\text { biodiversity }(n=114)\end{array}$ \\
\hline $\begin{array}{ll}1.1 .1 \\
\end{array}$ & $\begin{array}{l}\text { Sub-sub-hypothesis with establishment success of exotics as inverse } \\
\text { measure of resistance }(n=14)\end{array}$ \\
\hline 1.1 .2 & $\begin{array}{l}\text { Sub-sub-hypothesis with exotic species richness as inverse measure } \\
\text { of resistance }(n=57)\end{array}$ \\
\hline 1.1 .3 & $\begin{array}{l}\text { Sub-sub-hypothesis with abundance, biomass, or cover of exotics } \\
\text { as inverse measure of resistance }(n=30)\end{array}$ \\
\hline 1.1 .4 & $\begin{array}{l}\text { Sub-sub-hypothesis with spread of exotics as inverse measure of } \\
\text { resistance }(n=3)\end{array}$ \\
\hline 1.1 .5 & $\begin{array}{l}\text { Sub-sub-hypothesis with survival, growth, or recruitment of } \\
\text { exotics as inverse measure of resistance }(n=10)\end{array}$ \\
\hline
\end{tabular}




\begin{tabular}{|c|c|}
\hline Hypothesis no. & Description $^{\dagger}$ \\
\hline 1.2 & $\begin{array}{l}\text { Sub-hypothesis with Shannon index as measure of native } \\
\text { biodiversity }(n=1)\end{array}$ \\
\hline 1.3 & $\begin{array}{l}\text { Sub-hypothesis with species evenness as measure of native } \\
\text { biodiversity }(n=2)\end{array}$ \\
\hline 1.4 & $\begin{array}{l}\text { Sub-hypothesis with number of functional groups as measure of } \\
\text { native biodiversity }(n=8)\end{array}$ \\
\hline 1.5 & $\begin{array}{l}\text { Sub-hypothesis with a proxy (e.g. latitude) as measure of native } \\
\text { biodiversity }(n=4)\end{array}$ \\
\hline 2 & Island susceptibility hypothesis $(n=9)$ \\
\hline 3 & Invasional meltdown hypothesis $(n=30)$ \\
\hline 4 & Novel weapons hypothesis $(n=23)$ \\
\hline 5 & Enemy release hypothesis $(n=106)$ \\
\hline 5.1 & $\begin{array}{l}\text { Sub-hypothesis comparing invaded and native range of exotic } \\
\text { species }{ }^{\ddagger}(n=30)\end{array}$ \\
\hline 5.1 .1 & $\begin{array}{l}\text { Sub-sub-hypothesis saying that exotics are less infested in invaded } \\
\text { than native range }(n=21)\end{array}$ \\
\hline 5.1 .2 & $\begin{array}{l}\text { Sub-sub-hypothesis saying that exotics show a lower degree of } \\
\text { damage in invaded than native range }(n=9)\end{array}$ \\
\hline 5.2 & $\begin{array}{l}\text { Sub-hypothesis comparing exotic species with native } \text { species }^{\ddagger}(n= \\
45)\end{array}$ \\
\hline 5.2 .1 & $\begin{array}{l}\text { Sub-sub-hypothesis saying that exotics are less infested than native } \\
\text { species }(n=23)\end{array}$ \\
\hline 5.2 .2 & $\begin{array}{l}\text { Sub-sub-hypothesis saying that exotics show a lower degree of } \\
\text { damage than native species }(n=22)\end{array}$ \\
\hline 5.3 & $\begin{array}{l}\text { Sub-hypothesis comparing invasive exotic species with non- } \\
\text { invasive exotic species }{ }^{\ddagger}(n=9)\end{array}$ \\
\hline 5.3 .1 & $\begin{array}{l}\text { Sub-sub-hypothesis saying that invasive exotics are less infected } \\
\text { than non-invasive exotics }(n=3)\end{array}$ \\
\hline 5.3 .2 & $\begin{array}{l}\text { Sub-sub-hypothesis saying that invasive exotics show a lower } \\
\text { degree of damage than non-invasive exotics }(n=6)\end{array}$ \\
\hline 5.4 & $\begin{array}{l}\text { Sub-hypothesis saying that exotic species profit (e.g. in terms of } \\
\text { biomass) from the absence of enemies }(n=22)\end{array}$ \\
\hline 6 & Tens rule $(n=74)$ \\
\hline 6.1 & $\begin{array}{l}\text { Sub-hypothesis on the following transition in the invasion process: } \\
\text { transport } \rightarrow \text { release (or casual) }(n=7)\end{array}$ \\
\hline 6.2 & $\begin{array}{l}\text { Sub-hypothesis on the following transition in the invasion process: } \\
\text { release (or casual or introduction) } \rightarrow \text { establishment }(n=50)\end{array}$ \\
\hline 6.3 & $\begin{array}{l}\text { Sub-hypothesis on the following transition in the invasion process: } \\
\text { establishment } \rightarrow \text { spread (or pest) }(n=17)\end{array}$ \\
\hline
\end{tabular}

$\dagger$ Only those sub-hypotheses are described that were actually tested by the identified studies. Hypotheses and sub-hypotheses that were only tested by a few studies were not further subdivided for our analysis.

${ }^{\ddagger}$ See van Kleunen et al. (2010) for these types of comparisons. 


\section{The decline effect}

We also investigated the presence of a 'decline effect', asking if empirical support for each hypothesis has declined over time. The term 'decline effect' describes the phenomenon that published empirical support for a given hypothesis declines over time. The strength of empirical support is often measured as effect size, so in such cases a decline effect is observed if published effect sizes decline over time. The phenomenon itself has been known since the 1930s but is receiving wide attention now (Lehrer 2010; Schooler 2011). It still lacks an official name (Lehrer 2010) but many researchers call it 'decline effect' (Schooler 2011). One reason for the recent interest in this phenomenon is due to better availability of long-term data. The effect is known from several disciplines, especially medicine where the decline in apparent effects of different pharmaceuticals is alarming (Lehrer 2010). A decline effect has also been reported in psychology (Lehrer 2010; Schooler 2011) and ecology and evolution (Poulin 2000; Jennions and Møller 2002; Lehrer 2010), but to our knowledge it has never been investigated in the context of biological invasions.

Several possible explanations for the decline effect have been discussed; one is publication bias, as supporting evidence for a new hypothesis is more interesting and can thus be published easier and faster than data that question a new hypothesis (Poulin 2000; Jennions and Møller 2002; Lehrer 2010). Only when a hypothesis has become established (because it has been supported by several published studies) does it become interesting to publish data that question the hypothesis. Such changing motivations to publish supporting and questioning evidence for a given hypothesis can lead to a publication bias that changes over time, which can in turn lead to a decline effect.

A decline effect can also be caused by a bias in study organisms or systems (Poulin 2000; Jennions and Møller 2002). It seems likely that a certain phenomenon is first noticed and described for an organism (or system) where it is particularly strong, as researchers are especially interested in a phenomenon if it is of high importance for their model organism. After publishing their findings, they will look for the phenomenon in related organisms where its presence appears likely as well. As a result, early studies on a certain hypothesis tend to be done for organisms where positive results are expected. Only later will other organisms be tested.

There are also statistical and psychological explanations for the decline effect (Jennions and Møller 2002; Lehrer 2010). Most decline effects probably have multiple reasons, but differentiating them has been hampered by data availability (Schooler 2011). In fact, decline effects are currently unknown in most disciplines and await better investigation.

We tested for a decline effect by comparing the level of empirical support for early vs. recent studies of each major hypothesis. 'Early' studies are the first $-50 \%$ of studies published on a given hypothesis, whereas 'recent' studies are the latest $-50 \%$ of studies. The cut-off point was determined to be as close as possible to $50 \%$; it was not exactly $50 \%$, as papers published in the same year were not split. We then performed a Generalized Linear Model (GLM) analysis for ordinal dependent variables (multino- 
mial distribution, cumlogit link; PASW Statistics 2010, version 18.0.2) with 'support' (questioned, undecided, or supported) as dependent variable and with 'hypothesis' (biotic resistance hypothesis, island susceptibility hypothesis, ...) and 'time' (early or recent studies) as predictor variables.

\section{Results}

\section{Three of the six hypotheses have low support ...}

We found that three of the six focal hypotheses are supported by $>50 \%$ of available empirical tests (invasional meltdown: 77\%; novel weapons: 74\%; enemy release: $54 \%$ ), whereas the other three hypotheses are supported by $<30 \%$ of available empirical tests (biotic resistance: 29\%; tens rule: 28\%; island susceptibility: 11\%; Fig. 2). Hypotheses with higher empirical support are those that consider invader-ecosystem interactions, whereas the other hypotheses do not include these interactions and focus on either invaders (tens rule) or ecosystems (biotic resistance, island susceptibility). Our literature search returned many more empirical tests of biotic resistance $(n=129)$, enemy release $(n=106)$, and the tens rule $(n=74)$ than of invasional meltdown $(n=30)$, novel weapons $(n=23)$, and island susceptibility $(n=9)$.

\section{... and support is declining over time across hypotheses}

Comparing early to recent empirical tests of the six hypotheses showed that empirical support for these hypotheses has declined over time (Fig. 3). According to a Generalized Linear Model (GLM), observed empirical support significantly differs (1) among hypotheses $(p<0.001,5 \mathrm{DF}$, likelihood ratio chi-square $=60.52)$, thus statistically confirming differences mentioned in the previous section, and (2) between early and recent studies $(p<0.05,1 \mathrm{DF}$, likelihood ratio chi-square $=4.84)$. In other words, the decline in empirical support shown in Fig. 3 is statistically significant across the six hypotheses. The decline's intensity seems to differ among hypotheses - the differences in percent studies supporting each hypothesis between early and recent studies are as follows (depicted in Fig. 3): 5\% for biotic resistance, 25\% for island susceptibility, $41 \%$ for invasional meltdown, $25 \%$ for novel weapons, $10 \%$ for enemy release, and $10 \%$ for the tens rule. However, sample sizes are currently low for some hypotheses, so future tests are needed to clarify whether the decline's intensity really differs among hypotheses.

\section{Differences also exist among taxonomic groups and habitats}

Empirical support for the tens rule is stronger for plants and invertebrates than for vertebrates (Fig. 4), whereas support for biotic resistance, enemy release, and invasional 


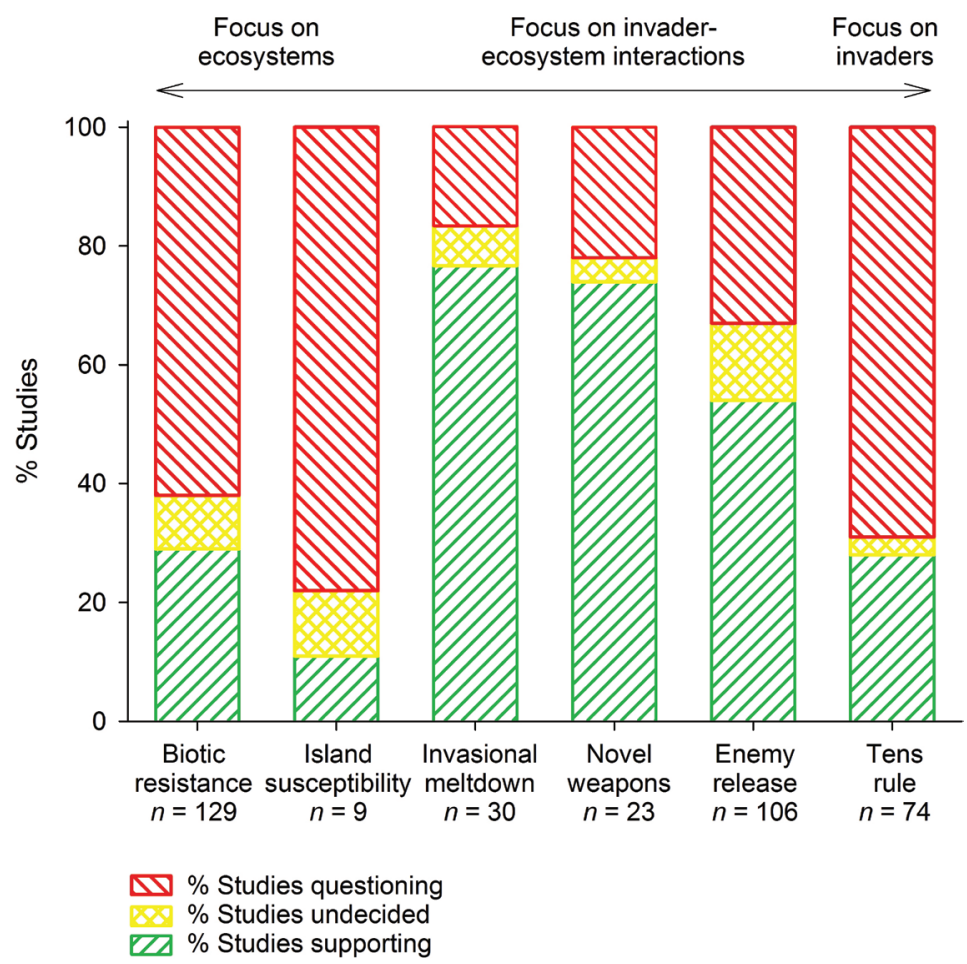

Figure 2. Overall level of empirical support for six of invasion biology's major hypotheses. Hypotheses focusing on ecosystems where invaders were introduced are on the left (biotic resistance, island susceptibility), the tens rule which focuses on the invaders themselves is on the right, and hypotheses considering invader-ecosystem interactions are in between (invasional meltdown, novel weapons, enemy release).

meltdown does not significantly differ among taxonomic groups. For island susceptibility and invasional meltdown, a sufficient number of empirical tests are currently available only for one taxonomic group each (Fig. 4).

Comparing studies of invaded terrestrial, freshwater, and marine habitats shows significant differences for biotic resistance and the tens rule: for these two hypotheses, support from marine studies is strongest (Fig. 5). We found no significant differences for invasional meltdown and enemy release, and did not test habitat differences for the two remaining hypotheses (island susceptibility and novel weapons), as empirical tests of these hypotheses are currently available only for terrestrial habitats.

\section{The big picture}

In sum, invasional meltdown currently has the highest level of support of the six hypotheses, with consistently high levels of support across taxa and habitats. Support for this hypothesis has substantially declined over time, but numbers of empirical studies 


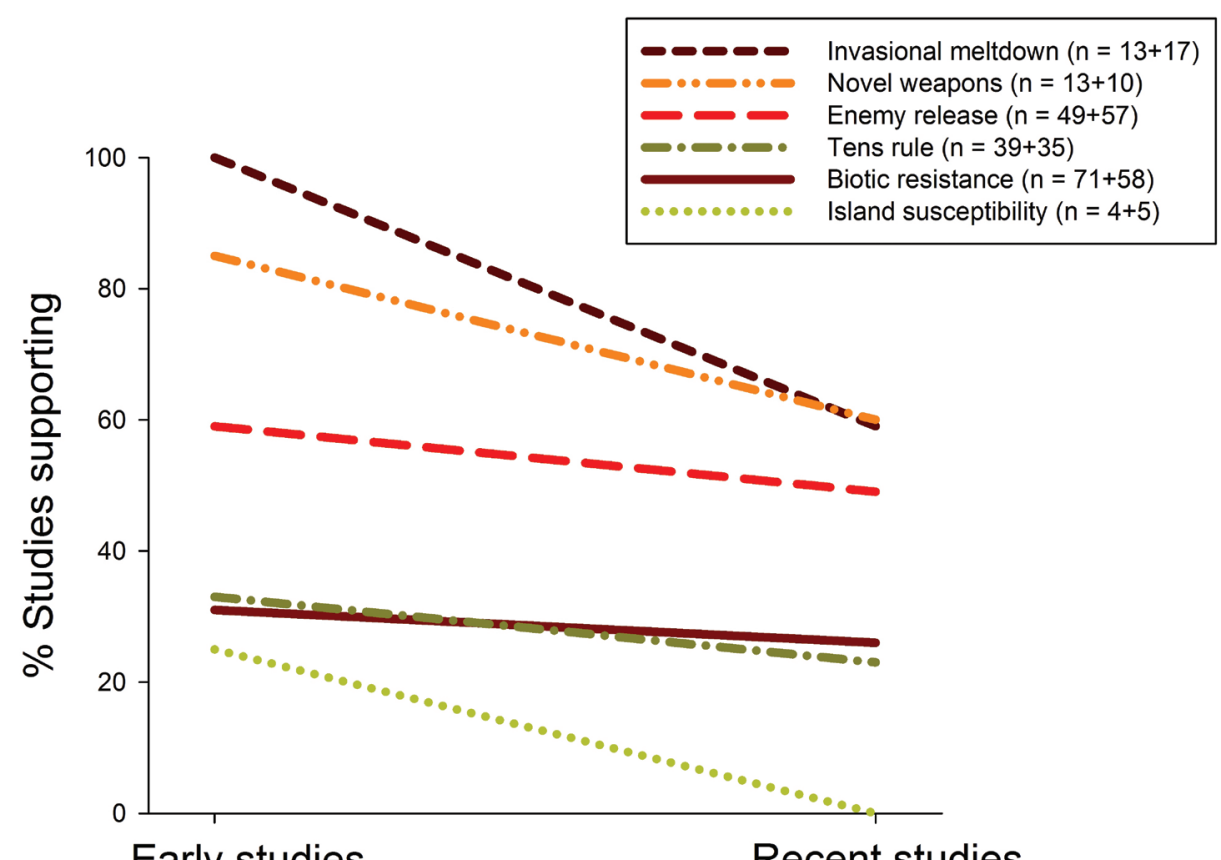

Figure 3. Level of empirical support for six of invasion biology's major hypotheses, subdivided for early and recent studies. Numbers of early and recent studies for each hypothesis are provided in the legend. To improve the figure's clarity, only \% studies supporting each hypothesis are shown here, and other studies are not further divided into those questioning and being undecided about each hypothesis (as in Figs 2, 4, 5). When statistically testing for a decline effect, however, all three levels of empirical support (supported, undecided, questioned) were considered. The decline effect shown here is statistically significant (Generalized Linear Model, likelihood ratio test, $p<0.05$ ).

are still limited, so it would be premature to assume that the decline will continue to be so substantial.

The novel weapons hypothesis reaches a similar overall level of support as the invasional meltdown hypothesis, but it has been tested only for terrestrial plants, so its applicability to animals and aquatic habitats is unclear. Empirical support for this hypothesis has markedly declined over time as well.

Enemy release has received mixed support from existing tests, and again, most tests have focused on terrestrial plants. When comparing early and recent studies on enemy release, however, there is only a slight decline in the frequency of supporting studies.

Biotic resistance, island susceptibility, and the tens rule all have low levels of empirical support. Support for biotic resistance is low across taxonomic groups, but most marine studies have reported supporting evidence: $55 \%$ of marine empirical tests have supported the biotic resistance hypothesis. The tens rule performs poorly overall, but 
(a) Biotic resistance

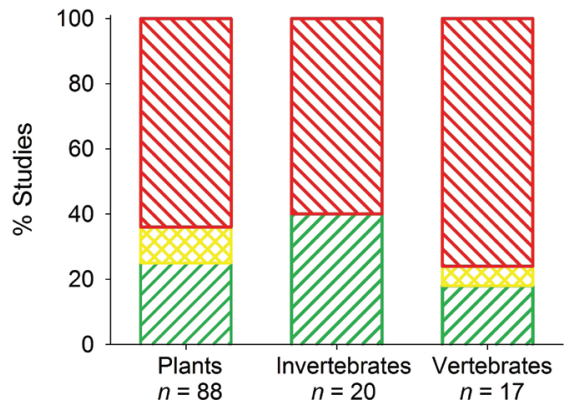

(c) Invasional meltdown

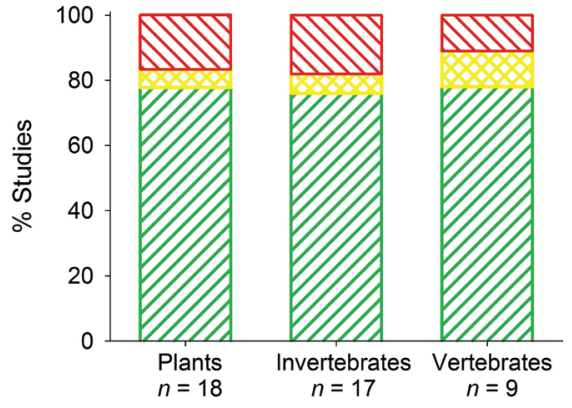

(e) Enemy release

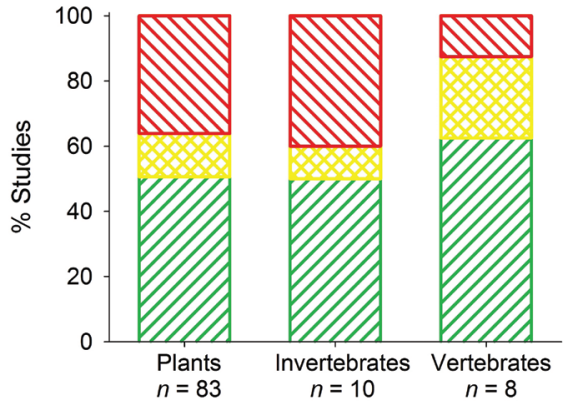

(b) Island susceptibility

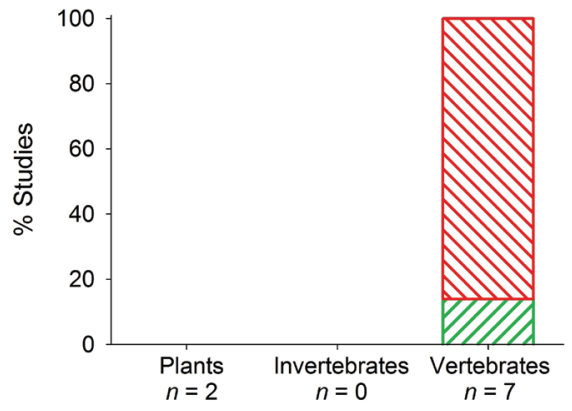

(d) Novel weapons

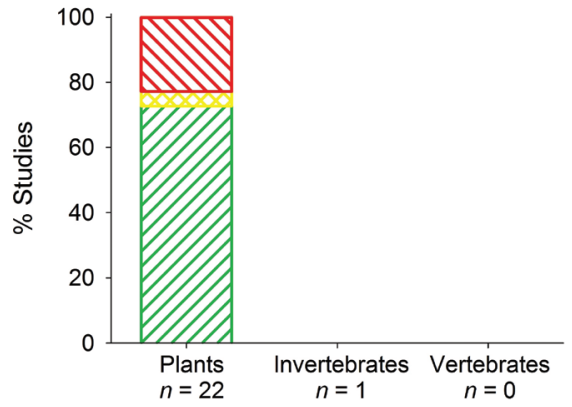

(f) Tens rule

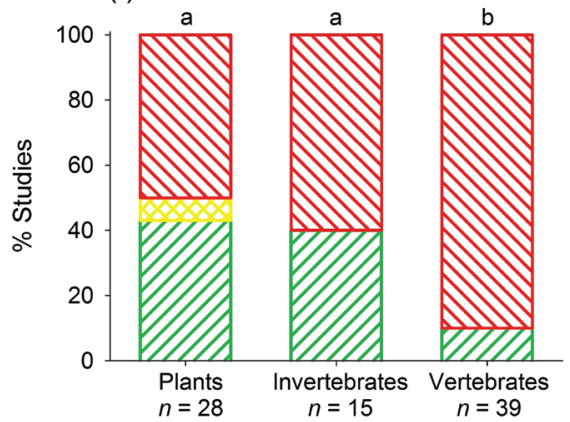

\% Studies questioning
$\%$ Studies undecided
$\%$ Studies supporting

Figure 4. Level of empirical support for six of invasion biology's major hypotheses, subdivided by taxonomic groups. The few cross-taxonomic studies that covered more than one of the three indicated taxonomic groups were counted for each group. Missing bars indicate lacking data: bars are shown only if at least five studies were carried out for a given hypothesis and taxonomic group. Letters in (f) indicate significant differences between taxonomic groups ( $U$ tests, $p<0.01$ ). No significant differences were observed for the other hypotheses. 
(a) Biotic resistance

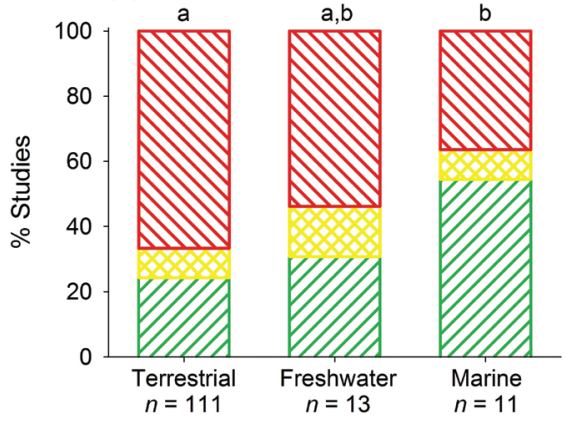

(c) Invasional meltdown

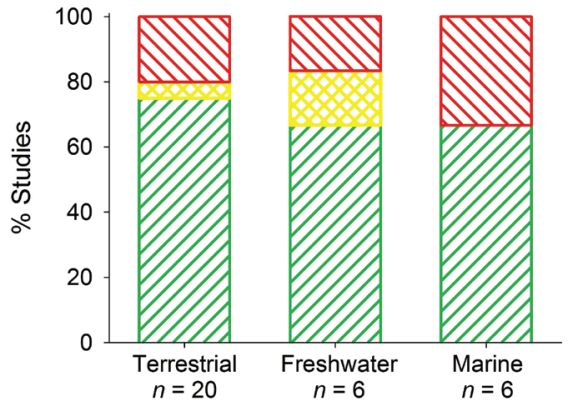

(e) Enemy release

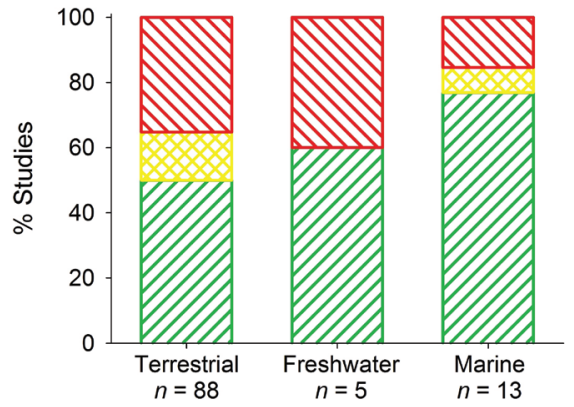

(b) Island susceptibility

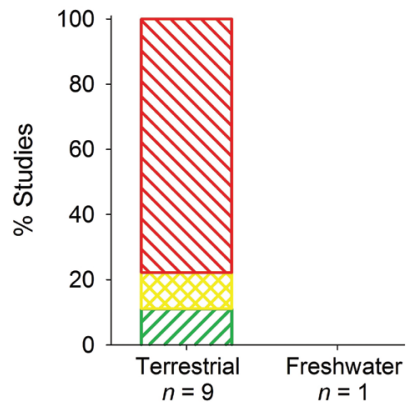

(d) Novel weapons

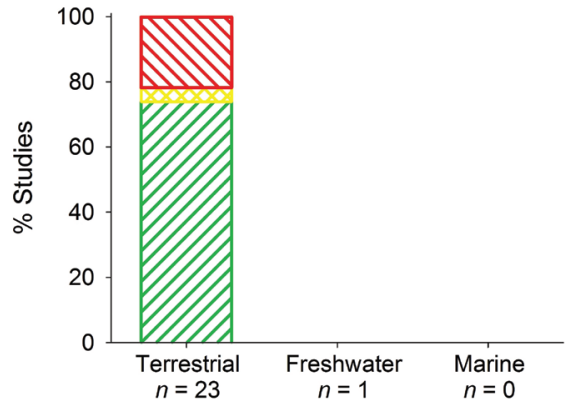

(f) Tens rule

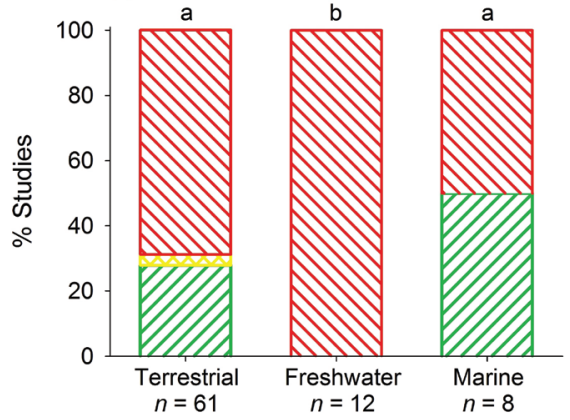

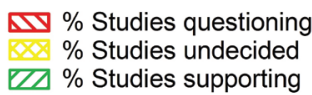

Figure 5. Level of empirical support for six of invasion biology's major hypotheses, subdivided by habitats. The few studies that covered more than one of the three habitats were counted for each habitat. Missing bars indicate lacking data: bars are only shown if at least 5 studies were carried out for a given hypothesis and habitat. Note that the island susceptibility hypothesis is not applicable to the marine habitat. Letters in (a) and (f) indicate significant differences between habitats ( $\mathrm{U}$ tests, $p<0.05$ ). No significant differences were observed for the other hypotheses. 
significant differences among taxa and habitats exist. The decline in empirical support for biotic resistance and the tens rule is small. The island susceptibility hypothesis has been tested mainly for terrestrial vertebrates (78\% of all studies, $67 \%$ on birds), and studies indicate almost no support, especially recent studies. This hypothesis has not been sufficiently tested for plants, invertebrates, and freshwater habitats.

\section{Discussion}

Our results suggest that empirical support for some major hypotheses in invasion biology is both doubtful and has declined over time. This is unfortunate, as both effective policy making and management of invasive species rely on sound hypotheses. For instance, many policy and management decisions depend on the potential risk posed by species introductions, which partly depends on the probability that introduced species become invasive. This probability is predicted to be low by the tens rule, but actual data suggest it can be high, depending on the taxonomic group and habitat in question. A similar consideration applies to the biotic resistance hypothesis which posits that diverse ecosystems are relatively resistant against invaders. Based on this hypothesis, it could be argued that no specific policy or management actions are required to protect diverse ecosystems, as they are inherently 'safe'. Yet, currently available evidence questions the resistance hypothesis, hence diverse ecosystems need to be protected against harmful invaders, too.

To our knowledge, this is the first broad comparative evaluation of multiple major invasion hypotheses. Several previous studies evaluated individual hypotheses, e.g. empirical data from plants were found to only weakly support the disturbance hypothesis which was not evaluated here (Moles et al. 2012), and empirical data from animals were found to not support the tens rule (Jeschke and Strayer 2005; Jeschke 2008). Here, we further show that empirical data from plants more frequently support the tens rule than data from animals, yet levels of support for this hypothesis do not exceed $50 \%$ across taxonomic groups and habitats. The tens rule differs from our other focal hypotheses in that it only attempts to describe a pattern rather than trying to explain it. Nonetheless, it is not better supported by empirical tests than the other hypotheses. Meta-analyses exist on the biotic resistance and enemy release hypotheses, but to our knowledge only for exotic plants (Liu and Stiling 2006; Levine et al. 2004). Using a broader perspective, our analysis provides insights into the relative success of hypotheses across taxonomic groups and habitats, suggesting which hypotheses are better supported by empirical evidence than others. It is possible to compare our results to previous analyses and reviews for each of our focal hypotheses, but going into details for each specific hypothesis is beyond the scope of this article. Instead, our review aims to provide results that help to broadly evaluate the current state of the discipline and suggest priorities for future research. 


\section{Four solutions to current challenges in invasion biology}

What is the way forward? Our results suggest four possible solutions to current challenges in invasion biology:

Solution 1 - Fill existing gaps in empirical tests of hypotheses. It is crucial to fill existing gaps in empirical studies on invasion biology's major hypotheses, such as those identified in this study for specific taxonomic groups and habitats (Figs 4, 5).

Solution 2 - Specify hypotheses for taxa and habitats. Despite the current shortage of empirical tests, our results already show that hypotheses differ in their applicability among taxonomic groups and habitats. It might be too much to expect that most hypotheses apply across all taxonomic groups and habitats. On the other hand, if a hypothesis applies only to a single taxon consisting of a few species (e.g. a genus or family), it is not too useful for the field in general. What would be useful instead is a general hypothesis that can be specified for given taxa and habitats, so that these variants of the hypothesis provide reliable predictions for each taxon and habitat. The hierarchy-of-hypotheses approach together with a subdivision of empirical tests according to taxonomic groups and habitats, as done here, are first steps into this direction. They allow us to better understand which hypothesis (and which version of which hypothesis) works best for which taxonomic group and habitat.

Solution 3 - Consider invader-ecosystem interactions. Hypotheses that do not consider invader-ecosystem interactions (e.g. biotic resistance, island susceptibility, tens rule) might benefit if they are revised to consider such interactions. For example, the biotic resistance hypothesis could be revised by considering key-lock effects (e.g. facilitation) between resident and introduced species, or the tens rule could be revised by considering the composition and functional structure of resident communities. Our results suggest that hypotheses addressing invader-ecosystem interactions have more potential to improve our understanding of biological invasions than those focusing solely on either invaders or characteristics of the new environment. The idea to develop a balanced approach to biological invasions that addresses both invaders and the new environment has been formulated before (Roy 1990; Heger and Trepl 2003; Richardson and Pyšek 2006; Schaefer et al. 2011), but to our knowledge, the current study is the first to bolster this idea with evidence across taxonomic groups and habitats. Further studies are, of course, needed to test if the predictive power of hypotheses really improves if they are revised to include invader-ecosystem interactions.

Solution $4-$ Reject revised hypotheses if they do not work. Some hypotheses will not be rescued by a specification for taxonomic groups and habitats (solution 2), a consideration of invader-ecosystem interactions (solution 3), or another form of revision. Hypotheses that still lack support after revision should be discarded, as we should not 
waste our time and resources to continue testing hypotheses that simply do not work. Instead, we should use our creativity to come up with fresh ideas and new hypotheses.

\section{Acknowledgements}

We thank Adam Petrusek and Radka Wildová for helpful discussions, Zuzana Sixtová for technical assistance, and Brad Murray, Steward Pickett, and an anonymous reviewer for comments. The hierarchy-of-hypotheses $(\mathrm{HoH})$ idea outlined here emerged both from our work on this study and discussions during the workshop "Tackling the emerging crisis of invasion biology: How can ecological theory, experiments, and field studies be combined to achieve major progress?" (March 2010 in Benediktbeuern, Germany; workshop of the specialist group "Theory in Ecology" of the Ecological Society of Germany, Austria and Switzerland, GfÖ), organized by TH, SH, Anna Liebaug, an JMJ. Many thanks to the workshop participants for their input! Financial support for this study was received from the Deutsche Forschungsgemeinschaft (DFG; JE 288/4-1). PP was supported by grant no. P504/11/1028 (Czech Science Foundation), long-term research development project no. RVO 67985939 (Academy of Sciences of the Czech Republic), institutional resources of Ministry of Education, Youth and Sports of the Czech Republic, and acknowledges support by the Praemium Academiae award from the Academy of Sciences of the Czech Republic.

\section{References}

Arnqvist G, Wooster D (1995) Meta-analysis: synthesizing research findings in ecology and evolution. Trends in Ecology and Evolution 10: 236-240.

Atwood JP, Meyerson LA (2011) Beyond EICA: understanding post-establishment evolution requires a broader evaluation of potential selection pressures. NeoBiota 10: 7-25. doi: 10.3897/neobiota.10.954

Blackburn TM, Lockwood JL, Cassey P. (2009) Avian invasions: the ecology and evolution of exotic bird species. Oxford University Press, Oxford, 320 pp.

Blumenthal D, Mitchell CE, Pyšek P, Jarošik V (2009) Synergy between pathogen release and resource availability in plant invasion. Proceedings of the National Academy of Sciences USA 106: 7899-7904. doi: 10.1073 pnas.0812607106

Cadotte MW (2006) Darwin to Elton: early ecology and the problem of invasive species. In: Cadotte MW, McMahon SM, Fukami T (Eds) Conceptual ecology and invasion biology: reciprocal approaches to nature. Springer, Dordrecht, 15-33.

Callaway RM, Aschehoug ET (2000) Invasive plants versus their new and old neighbors: a mechanism for exotic invasion. Science 290: 521-523.

Callaway RM, Ridenour WM (2004) Novel weapons: invasive success and the evolution of increased competitive ability. Frontiers in Ecology and the Environment 2: 436-443. 
Catford JA, Jansson R, Nilsson C (2009) Reducing redundancy in invasion ecology by integrating hypotheses into a single theoretical framework. Diversity and Distributions 15: 22-40. doi: 10.1111/j.1472-4642.2008.00521.x

Colautti RI, Ricciardi A, Grigorovich I, MacIsaac HJ (2004) Is invasion success explained by the enemy release hypothesis? Ecology Letters 7: 721-733. doi: 10.1111/j.14610248.2004.00616.x

Darwin C (1859) On the origin of species by means of natural selection, or the preservation of favoured races in the struggle for life. Murray, London, $502 \mathrm{pp}$.

Davis MA (2006) Invasion biology 1958-2005: the pursuit of science and conservation. In: Cadotte MW, McMahon SM, Fukami T (Eds) Conceptual ecology and invasion biology: reciprocal approaches to nature. Springer, Dordrecht, 35-64.

Dietz H, Edwards PJ (2006) Recognition that causal processes change during plant invasion helps explain conflicts in evidence. Ecology 87: 1359-1367.

Elton CS (1958) The ecology of invasions by animals and plants. Methuen, London, 181 pp.

Fridley JD, Stachowicz JJ, Naeem S, Sax, DF, Seabloom EW, Smith MD, Stohlgren TJ, Tilman D, Von Holle B. (2007) The invasion paradox: reconciling pattern and process in species invasions. Ecology 88: 3-17.

Gurevitch J, Hedges LV (2001) Meta-analysis: combining the results of independent experiments. In: Scheiner SM, Gurevitch J (Eds) Design and analysis of ecological experiments. Oxford University Press, Oxford, 347-369.

Heger T, Trepl L (2003) Predicting biological invasions. Biological Invasions 5: 313-321.

Hierro JL, Maron JL, Callaway RM (2005) A biogeographical approach to plant invasions: the importance of studying exotics in their introduced and native range. Journal of Ecology 93: 5-15. doi: 10.1111/j.1365-2745.2004.00953.x

Hulme PE, Pyšek P, Nentwig W, Vilà M (2009) Will threat of biological invasions unite the European Union? Science 324: 40-41. doi: 10.1126/science.1171111

Ives AR, Carpenter SR (2007) Stability and diversity of ecosystems. Science 31: 58-62. doi: 10.1126/science. 1133258

Jennions MD, Møller AP (2002) Relationships fade with time: a meta-analysis of temporal trends in publication in ecology and evolution. Proceedings of the Royal Society London Series B 269: 43-48.

Jeschke JM (2008) Across islands and continents, mammals are more successful invaders than birds. Diversity and Distributions 14: 913-916. doi: 10.1111/j.1472-4642.2008.00488.x

Jeschke JM, Genovesi P (2011) Do biodiversity and human impact influence the introduction or establishment of alien mammals? Oikos 120: 57-64. doi: 10.1111/j.16000706.2010.18621.x

Jeschke JM, Gómez Aparicio L, Haider S, Heger T, Lortie CL, Pyšek P, Strayer DL (2012) Taxonomic bias and lack of cross-taxonomic studies in invasion biology. Frontiers in Ecology and the Environment 10: 349-350. doi: 10.1890/12. WB.016

Jeschke JM, Strayer DL (2005) Invasion success of vertebrates in Europe and North America. Proceedings of the National Academy of Sciences USA 102: 7198-7202. doi: 10.1073/ pnas.0501271102 
Keane RM, Crawley MJ (2002) Exotic plant invasions and the enemy release hypothesis. Trends in Ecology and Evolution 17: 164-170.

Kettunen M, Genovesi P, Gollasch S, Pagad S, Starfinger U, ten Brink P, Shine C (2009) Technical support to EU strategy on invasive alien species (IAS) - Assessment of the impacts of IAS in Europe and the EU. Institute for European Environmental Policy, Brussels, 44 pp.

Lehrer J (2010) The truth wears off. New Yorker Dec 13: 52-57.

Levine JM, Adler PB, Yelenik SG (2004) A meta-analysis of biotic resistance to exotic plant invasions. Ecology Letters 7: 975-989. doi: 10.1111/j.1461-0248.2004.00657.x

Levine JM, D’Antonio CM (1999) Elton revisited: a review of evidence linking diversity and invasibility. Oikos 87: 15-26.

Liu H, Stiling P (2006) Testing the enemy release hypothesis: a review and meta-analysis. Biological Invasions 8: 1535-1545. doi: 10.1007/s10530-005-5845-y

Lockwood JL, Hoopes MF, Marchetti MP (2007) Invasion ecology. Blackwell, Malden, 304 pp.

Lonsdale WM (1999) Global patterns of plant invasions and the concept of invasibility. Ecology 80: 1522-1536.

Mack RN, Simberloff D, Lonsdale WM, Evans H, Clout M, Bazzaz FA (2000) Biotic invasions: causes, epidemiology, global consequences, and control. Ecological Applications 10: 689-710.

Maron JL, Vilà M (2001) When do herbivores affect plant invasion? Evidence for the natural enemies and biotic resistance hypotheses. Oikos 95: 361-373.

Mitchell CE, Power AG (2003) Release of invasive plants from fungal and viral pathogens. Nature 421: 625-627. doi: 10.1038/nature01317

Moles AT, Flores-Moreno H, Bonser SP, Warton DI, Helm A, Warman L, Eldridge DJ, Jurado E, Hemmings FA, Reich PB, Cavender-Bares J, Seabloom EW, Mayfield MM, Sheil D, Djietror JC, Peri PL, Enrico L, Cabido MR, Setterfield SA, Lehmann CER, Thomson FJ (2012) Invasions: the trail behind, the path ahead, and a test of a disturbing idea. Journal of Ecology 100: 116-127. doi: 10.1111/j.1365-2745.2011.01915.x

Pimentel D, Zuniga R, Morrison D (2005) Update on the environmental and economic costs associated with alien-invasive species in the United States. Ecological Economics 52: 273 288. doi: 10.1016/j.ecolecon.2004.10.002

Poulin R (2000) Manipulation of host behaviour by parasites: a weakening paradigm? Proceedings of the Royal Society London Series B 267: 787-792.

Pyšek P, Hulme P (2009) Invasion biology is a discipline that's too young to die. Nature 460: 324-324. doi: 10.1038/460324b

Pyšek P, Richardson DM (2010) Invasive species, environmental change and management, and health. Annual Review of Environment and Resources 35: 25-55. doi: 10.1146/annurevenviron-033009-095548

Pyšek P, Richardson DM, Pergl J, Jarošík V, Sixtová Z, Weber E (2008) Geographical and taxonomic biases in invasion ecology. Trends in Ecology and Evolution 23: 237-244. doi: 10.1016/j.tree.2008.02.002

Richardson DM, Pyšek P (2006) Plant invasions: merging the concepts of species invasiveness and community invasibility. Progress in Physical Geography 30: 409-431. doi: 10.1191/0309133306pp490pr 
Richardson DM, Pyšek P (2008) Fifty years of invasion ecology - the legacy of Charles Elton. Diversity and Distributions 14: 161-168. doi: 10.1111/j.1472-4642.2008.00464.x

Roy J (1990) In search of the characteristics of plant invaders. In: di Castri F, Hansen AJ, and Debussche M (Eds) Biological invasions in Europe and the Mediterranean Basin. Kluwer, Dordrecht, 335-352.

Sax DF, Stachowicz JJ, Brown JH, Bruno JF, Dawson MN, Gaines SD, Grosberg RK, Hastings A, Holt RD, Mayfield MM, O'Connor MI, Rice WR (2007) Ecological and evolutionary insights from species invasions. Trends in Ecology and Evolution 22: 465-471. doi: 10.1016/j.tree.2007.06.009

Schaefer H, Hardy OJ, Silva L, Barraclough TG, Savolainen V (2011) Testing Darwin's naturalization hypothesis in the Azores. Ecology Letters 14: 389-396. doi: 10.1111/j.14610248.2011.01600.x

Schooler J (2011) Unpublished results hide the decline effect. Nature 470: 437-437. doi: $10.1038 / 470437 \mathrm{a}$

Shea K, Chesson P (2002) Community ecology theory as a framework for biological invasions. Trends in Ecology and Evolution 17: 170-176.

Simberloff D (1995) Why do introduced species appear to devastate islands more than mainland areas? Pacific Science 49: 87-97.

Simberloff D, Von Holle B (1999) Positive interactions of nonindigenous species: invasional meltdown? Biological Invasions 1: 21-32.

Torchin ME, Lafferty KD, Dobson AP, McKenzie VJ, Kuris AM (2003) Introduced species and their missing parasites. Nature 421: 628-630. doi: 10.1038/nature01346

van Kleunen M, Dawson W, Schlaepfer D, Jeschke JM, Fischer M (2010) Are invaders different? A conceptual framework of comparative approaches for assessing determinants of invasiveness. Ecology Letters 13: 947-958. doi: 10.1111/j.1461-0248.2010.01503.x

Williamson M (1996) Biological invasions. Chapman \& Hall, London, 244 pp.

Williamson M, Brown KC (1986) The analysis and modelling of British invasions. Philosophical Transactions of the Royal Society London Series B 314: 505-522. 